\title{
Optimal dose horse antithymocyte globulin for the treatment of adult patients with aplastic anemia: a prospective randomized comparative study
}

Zalina Fidarova, Elena Mikhailova, Hunan Julhakyan, Vera Troitskaya, Anastasia Abramova, Anton Luchkin,

Elena Parovichnikova, Valeriy Savchenko

It is generally known that horse antithymocytic globulin (ATGAM) are more effective for treatment of pts with acquired $A A$ than rabbit ATG. There is no doubt, that dose regime $160 \mathrm{mg} / \mathrm{kg}$ ATGAM Improves response for young pts after $1^{\text {st }}$ course. Optimal ATGAM dose is important unsettled issue to achieve as soon as possible remission in adult pts and reduce time to alloBMT in refractory cases

\section{Aim}

Aim of this study is to evaluate effectiveness and response rate on $\mathrm{ATGAM}^{*} 20$ and $\mathrm{ATGAM}^{*} 40$ dose in adult pts with aplastic anemia

\section{Design}

Thirty-three patients with acquired AA (NSAA/SAA) required in combined IST with ATGAM and cyclosporin A were included into the prospective study since 2013 year
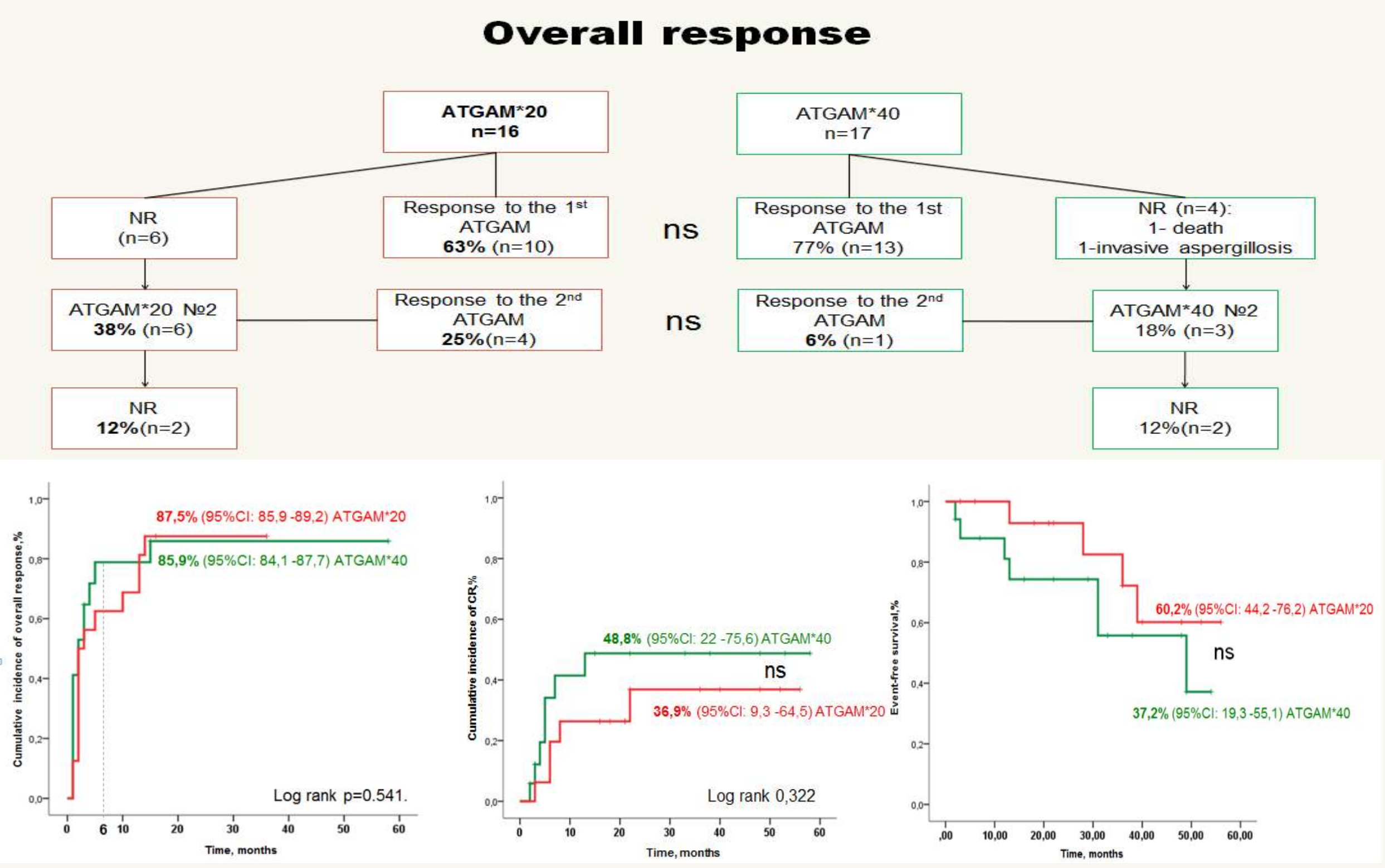

\begin{tabular}{|c|c|c|c|}
\hline & ATGAM*20 & ATGAM $^{*} 40$ & $\mathrm{p}$ \\
\hline Pts, $n$ & 16 & 17 & \\
\hline Age, median, years & $26(20-34)$ & $25(19-35)$ & 0,423 \\
\hline MIF, n & 9/7 & $10 / 7$ & 0,699 \\
\hline \multicolumn{4}{|l|}{ Severity of $A A$} \\
\hline SAA/NSAA, $n$ & $6 / 10$ & $7 / 10$ & 0,445 \\
\hline \multicolumn{4}{|l|}{ Hemogram } \\
\hline ANC, x10B9/I, median (min-max) & $\begin{array}{c}0,68 \\
(0,01-2,26)\end{array}$ & $\begin{array}{c}0,51 \\
(0,09-1,34)\end{array}$ & 0,423 \\
\hline ARC, x10B9/l, median (min-max) & $\begin{array}{c}30,9 \\
(5,2-72,5)\end{array}$ & $\begin{array}{c}17,04 \\
(1,87-35,2)\end{array}$ & 0,182 \\
\hline $\mathrm{SF}, \mathrm{ng} / \mathrm{ml}$, median (min-max) & $\begin{array}{c}663 \\
(15,9-1549)\end{array}$ & $\begin{array}{c}627 \\
(78-1988)\end{array}$ & 0,181 \\
\hline PNH-clone, $n$ & $11 / 16(69 \%)$ & $15 / 17(88 \%)$ & 0,56 \\
\hline LDH, E/l & $\begin{array}{c}407 \\
(213-711)\end{array}$ & $\begin{array}{c}344,8 \\
(321-481)\end{array}$ & 0,773 \\
\hline Interval diagnosis - IST, months, median (min-max) & $\begin{array}{c}3 \\
(1-45)\end{array}$ & $\begin{array}{c}3 \\
(1-15)\end{array}$ & 0,58 \\
\hline Observation time, months, median (min-max & $29(5-45)$ & $33(3-58)$ & 0,789 \\
\hline
\end{tabular}

\section{Results}

The frequency of reaction to drug administration, serum sickness and infections complications were comparable in both groups. Cumulative rate of overall response was higher in ATGAM ${ }^{\star} 20$ group $(87,5 \%(95 \% \mathrm{Cl}: 85,9-89,2))$ vs $\mathrm{ATGAM}^{*} 40$ group $(85,9 \%(95 \% \mathrm{Cl}: 84,1-87,7))$. The second course of $A_{T G A M}{ }^{\star} 20$ were effective in 4 of 6 pts who did not achieve response after $1^{\text {st }}$ course, however, the second course of ATGAM* 160 were not effective in 2 of 3 pts. Complete response rate after IST of ATGAM $^{*} 40$ was $48,8 \%(95 \% \mathrm{Cl}: 22-75,6)$, but in group ATGAM*20 it was $36,9 \%(95 \% \mathrm{Cl}: 9,3-64,5) \quad(p>0,05)$ even after 2 nd course. It is important to note, that median time to achieve response was less in ATGAM*40 (2,7vs6,2 months respectively)

\section{Conclusion}

In conclusion we propose that Low-dose of ATGAM for treatment of adult AA patients were effective but not sufficient to reduce timing before allo-BMT.
We are presenting a single-center experience. The median of observation time (3-58) months. All pts were ATGAM $^{*} 20$ (ATGAM $20 \mathrm{mg} / \mathrm{kg} /$ day $1-5$ days, n=16) and ATGAM 40 (ATGAM 40 significant differences between two groups in such parameters as: mediane age (26vs25 years); gender (M/W: 9/7 vs 10/7); severity (NSAA/SAA: $10 / 6$ vs $10 / 7$ ); median of Grans (0,62vs0,58 $\left.\times 10^{9} / \mathrm{l}\right)$ and Ret $(30,1$ vs ( pts); median time to the start of IST after diagnosis were 3 months in both groups 